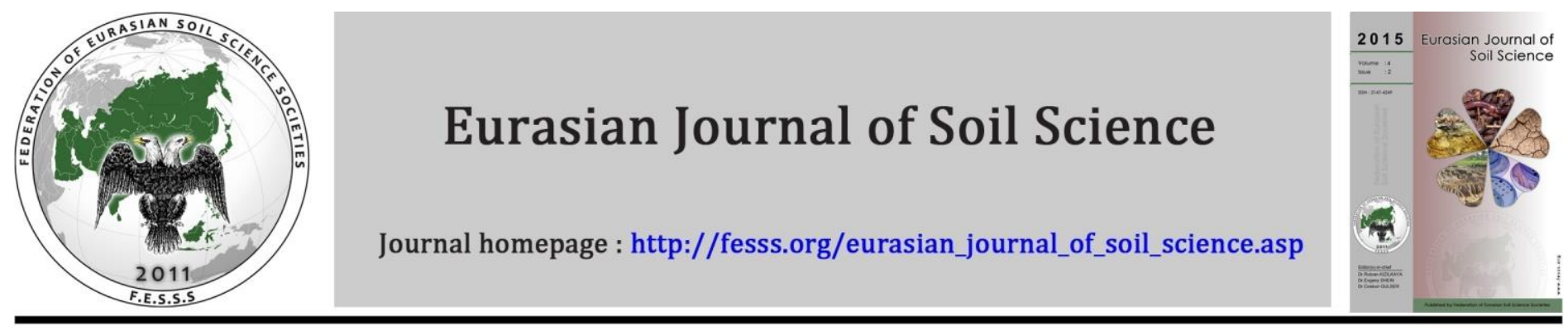

\title{
How the sorption of benzene in soils contaminated with aromatic hydrocarbons is affected by the presence of biofuels
}

\author{
Maria Manuela Carvalho a,b, Maria Cristina Vila a,*, Fernanda Rohden a, \\ Mónica Rosas a, Joana Dias c, Teresa Oliva-Teles b, Anthony Danko a, \\ Cristina Delerue-Matos ${ }^{b}$, António Fiuza a \\ ${ }^{a}$ CIGAR, Faculty of Engineering, University of Porto, Portugal \\ b REQUIMTE, Institute of Engineering of Porto, Polytechnic Institute of Porto, Portugal \\ c LEPABE, Faculty of Engineering, University of Porto, Portugal \\ d CERENA, Technical Institute of Lisbon, Portugal
}

\begin{abstract}
The increasing use of biofuels as additives to gasoline may have potential indirect effects on the efficiency of soil remediation technologies used to remediate fuel spills. This problem has not yet been studied. Sorption is one of the controlling processes in soil remediation. The effect of biofuels on sorption and phase distribution of contaminants by different natural soils has not been reported on the literature. The present work examines how two different biofuels, nbutanol and soybean biodiesel, affect benzene sorption in two naturally occurring subsoils (granite and limestone). Sorption isotherms were made with soils deliberately contaminated with benzene, benzene and n-butanol and benzene plus biodiesel, using lab-scale reactors operated at constant temperature, each one loaded with 700 grams of wet sterilized soil. For each type of soil, five isotherms were determined corresponding to different contamination profiles. It was concluded that sorption was strongly affected by the nature of the soil. The partition of benzene into the different phases of the soil was significantly affected by the presence of biofuels. The experimental data was fitted to conventional sorption models, Freundlich, Langmuir and a second order polynomial. Model parameters were determined using a non-linear least squares (NLLS) optimization algorithm and showed a good agreement between experimental and fitted data.
\end{abstract}

Keywords: Sorption, soils, benzene, biofuels

(C) 2015 Federation of Eurasian Soil Science Societies. All rights reserved

\section{Introduction}

In an attempt to reduce $\mathrm{CO}_{2}$ emissions, in the last years the $\mathrm{EU}$ adopted policies that favor the promotion and development of biofuels. From the point of view of soil contamination, these practices created a new concern that gasoline spills could result in the future co-contamination of biofuels and gasoline components such as benzene. Although there already have been some studies on the impact of biofuels on BTEX biodegradation, there is still controversy on the subject (Indumathy and Cupples, 2013). However, the effect of biofuels on sorption and phase distribution of contaminants by different natural soils are not referred in the literature. Thus, it is relevant to study the effects of the presence of biofuels on transport and partition mechanisms

\footnotetext{
${ }^{*}$ Corresponding author.

CIGAR, Faculty of Engineering, University of Porto, F419 Rua Roberto Frias, Porto 4200-465 Portugal
}

Tel.: +351220413167

E-mail address: mvila@fe.up.pt

ISSN: $2147-4249$ 
through the different soil phases. The effect of ethanol on the fate of fuel components in the environment has been studied mainly in terms of biodegradation, although sometimes with contradictory results. Mariano et al. $(2009,2010)$ obtained similar conflicting results for the biodegradation of fuels with n-butanol. Schaefer et al. (2010) assessed how the addition of iso-butanol to gasoline impacts the biodegradation of BTEX when present as co-contaminants. Ugwoha and Andresen (2013) reported the impact of organic matter on the sorption and on the solid-liquid phases distribution of gasoline blended with $20 \%$ butanol in sandy soils, having concluded that the presence of butanol reduces the retention capacity of organic matter in the vadose zone, thus potentially increasing the potential for groundwater contamination. Albergaria et al. $(2010,2012)$ studied the equilibrium isotherms of four samples of a prepared soil that differed in the moisture content and were contaminated with different volatile organic compounds (benzene, toluene, ethylbenzene, xylene, trichloroethylene and perchloroethylene) and aimed to evaluate the residual concentration of each contaminant in the solid phase after soil vapor extraction tests. In this study the authors concluded that the contaminant concentration in the gas phase was highly influenced by its vapor pressure and that increasing the soil moisture content reduces the ability of the monolayer and consequently the adsorption capacity of the soil due to the reduction of the contact between the gas phase and the solid matrix. In addition, Cheng et al. (2012) showed that hydrophobic micro-pores, which are ubiquitous in clay minerals such as kaolinite, determined the sorption processes (adsorption and desorption which are controlled by molecular size, polarity and diffusivity) of organic contaminants in subsurface geological media.

The aim of the present work is to study how biofuels, namely n-butanol and soybean biodiesel, affect benzene sorption in naturally occurring mineral soils (granite and limestone). To achieve this, an experimental plan constituted by ten different sorption conditions was implemented. Sorption mathematical models, which included the two most widely used (Freundlich and Langmuir) and also a second order polynomial equation were used to fit the experimental data using a non-linear least squares (NLLS) optimization algorithm. The widespread usage of Freundlich and Langmuir models can be partially explained by the apparent simplicity how fitting parameters can be estimated by linearization (Kinniburgh, 1986). However, as linearization is almost always unsuitable for fitting the Langmuir equation when small values (near zero) are present, a non-linear method for minimizing the least squares deviations was used.

\section{Material and Methods}

\section{Materials}

Benzene and n-butanol with purity greater than 99.5\%, were obtained from Panreac Quimica. Soybean biodiesel was synthetized by homogeneous alkali transesterification (Dias, 2008); its characteristics were determined according to the European biodiesel standard EN 14214. The samples of granitic soil (SR) were collected at 2-3 m depth in the Porto region (Portugal) from a recent slope excavation. Limestone samples (CL) were collected in a quarry in Souselas, Portugal, and its size distribution was arranged in order to match a pre-set similar to that measured for granite.

\section{Analytical Methods}

Benzene concentrations were determined by isothermal gas chromatography using a GC-Shimadzu-2014 chromatograph, equipped with a FID and a 60/80 Carbopack B support $(2.4 \mathrm{~m} \times 3.18 \mathrm{~mm} \times 2.1 \mathrm{~mm})$ column, with nitrogen as the carrier gas. The operating temperatures were $200{ }^{\circ} \mathrm{C}$ for both injector and detector and $150{ }^{\circ} \mathrm{C}$ for the oven. A sample volume of $200 \mu \mathrm{L}$ of air phase was injected in splitless mode. Sorption tests were performed in Erlenmeyer flasks of $1000 \mathrm{~mL}$ sealed with Teflon valves (Mininert@).

Soil samples were stored in appropriate containers protected from light at room temperature. Standard methodologies were used for soil characterization: particle size distribution (LNEC E196/1966), particle density (NP83/1965), bulk density (ASTM D4531-86), porosity (calculated through bulk and particle densities), maximum density and optimal water content (LNEC E197/1966), water content (NP84/1965), $\mathrm{pH}$ and conductivity at $25^{\circ} \mathrm{C}[15,16]$. Total organic carbon (TOC) was determinate by TOC-VCSN (Shimadzu) coupled to a Solid Sample Module SSM-5000 A (Shimadzu). The major elements were analyzed by X-ray energy dispersive fluorescence, the mineralogical composition by X-ray diffraction and the loss on ignition was also determined in an accredited external laboratory. 


\section{Equilibrium isotherms}

Sorption isotherms were studied using soils contaminated with benzene, benzene and n-butanol and benzene plus biodiesel at $25{ }^{\circ} \mathrm{C}$. The experiments were performed in lab-scale reactors each one loaded with 700 grams of wet sterilized soil. The final moisture content was obtained by adding sterilized water to achieve $25 \%$ for granitic soil and $11 \%$ for limestone. For each soil type, five isotherms were determined corresponding to different contamination profiles according to Table 1.

Table 1. Experimental contamination levels

\begin{tabular}{lccccc}
\hline Range of benzene added (mg) & $0.35-153.5$ & $0.35-193.0$ & $0.35-193.0$ & $0.35-193.0$ & $0.35-193.0$ \\
\hline n-Butanol (mg) & 0 & 162 & 810 & 0 & 0 \\
\hline Biodiesel (mg) & 0 & 0 & 0 & 175 & 877 \\
\hline
\end{tabular}

Biodiesel and n-butanol were used as previous contaminants. The addition of benzene was made by successive increments, from the minimum to the maximum values referred in the previous table. The time for each addition was defined by the equilibrium conditions. Contamination levels were considered stabilized when the concentration in the gas phase varied less than $5 \%$ in two consecutive days. The equilibrium isotherms were obtained by plotting the concentration of benzene in the gas phase $\left(\mathrm{C}_{\text {gas }}\right)$ versus its concentration in the soil matrix $\left(\mathrm{C}_{\text {soil }}\right)$. The concentration of benzene in the soil matrix is calculated using equation (1) to (5).

$$
\begin{array}{r}
\mathrm{C}_{\mathrm{aq}}=\mathrm{C}_{\mathrm{ggs}} \div \mathrm{H} \\
\mathrm{M}_{\mathrm{aq}}=\mathrm{C}_{\mathrm{aq}} \times \mathrm{V}_{\mathrm{aq}} \\
\mathrm{M}_{\mathrm{gas}}=\mathrm{C}_{\mathrm{gas}} \times \mathrm{V}_{\mathrm{ggs}} \\
\mathrm{M}_{\mathrm{soil}}=\mathrm{M}_{\text {tot }}-\mathrm{M}_{\mathrm{gas}}-\mathrm{M}_{\mathrm{aq}} \\
\mathrm{C}_{\mathrm{goil}}=\mathrm{M}_{\mathrm{goil}} \div \mathrm{M}_{5}
\end{array}
$$

where $\mathrm{C}_{\mathrm{aq}}$ is the concentration of the contaminant in aqueous phase ( $\mathrm{mg} \mathrm{L}^{-1}$ ), $\mathrm{C}_{\text {gas }}$ is the concentration of the contaminant in the gas phase $\left(\mathrm{mg} \mathrm{L}^{-1}\right), \mathrm{H}$ is the contaminant's dimensionless Henry's constant at the temperature of the experiment $\left(25^{\circ} \mathrm{C}\right), \mathrm{M}_{\mathrm{aq}}$ is the mass of the contaminant in aqueous phase $(\mathrm{mg}), \mathrm{V}_{\mathrm{aq}}$ is the volume of the aqueous phase (L), $M_{\text {gas }}$ is the mass of the contaminant in gas phase (mg), $V_{\text {gas }}$ is the volume of the gas phase (L), $M_{\text {soil }}$ is the mass of the contaminant in the solid phase (mg), $M_{\text {tot }}$ is the total mass of the contaminant (mg), $\mathrm{C}_{\text {soil }}$ is the concentration of the contaminant in the solid phase $\left(\mathrm{mg} \mathrm{kg}^{-1}\right)$; $\mathrm{M}_{\mathrm{s}}$ is the mass of solid phase (mg).

The mathematical models, Freundlich, Langmuir and polynomial, described in equations number 6, 7 and 8 respectively, were fitted to the experimental data in order to determine the best isotherm (Perry, 1984). The generalized reduced gradient (GRG) method of non-linear least squares minimization was used to obtain the optimal parameters for each model, namely the Freundlich constant $\left(\mathrm{K}_{\mathrm{F}}\right)$ and exponent $(\mathrm{n})$, the Langmuir equilibrium constant $\left(\mathrm{K}_{\mathrm{L}}\right)$ and its asymptotic maximum solid-phase concentration capacity (b), and the coefficients of the polynomial degrees $\left(a_{0}, a_{1}\right.$ and $\left.a_{2}\right)$.

$$
\begin{aligned}
& \mathrm{C}_{\mathrm{soil}}=\mathrm{K}_{\mathrm{F}} \times \mathrm{C}_{\mathrm{ggas}}^{\mathrm{n}} \\
& \mathrm{C}_{\mathrm{g}}=\mathrm{b} \frac{\mathrm{K}_{\mathrm{L}} w \mathrm{C}_{\mathrm{g}}}{1+\mathrm{K}_{\mathrm{L}} \times \mathrm{C}_{\mathrm{g}}} \\
& \mathrm{C}_{\text {goil }}=\mathrm{a}_{2} \mathrm{C}_{\mathrm{gas}}^{2}+\mathrm{a}_{1} \mathrm{C}_{\mathrm{gax}}+\mathrm{a}_{0}
\end{aligned}
$$




\section{Results and Discussion}

\section{Soil Characterization}

Physical, chemical, mineralogical and geotechnical characterization of the two studied soils is summarized in Table 2. The granite sample was a sandy-silty soil predominantly composed by aluminosilicates with high grade of kaolinization, large grain size distribution, low electrical conductivity, very low natural organic matter, and slightly acidic. The limestone sample was a sandy-clay soil mainly composed by calcite, low natural organic matter with a neutral $\mathrm{pH}$.

Table 2. Soils properties

\begin{tabular}{llllll}
\hline & Granite & Limestone & & Granite & Limestone \\
\hline Bulk density $\left(\mathrm{kg} \mathrm{m}^{-3}\right)$ & 1060 & 1530 & $\mathrm{SiO}_{2}(\%)$ & 50.72 & 11.14 \\
Porosity (\%) & 60 & 44 & $\mathrm{Al}_{2} \mathrm{O}_{3}(\%)$ & 23.64 & 2.74 \\
$\mathrm{pH}$ & 5.8 & 6.8 & $\mathrm{Fe}_{2} \mathrm{O}_{3}(\%)$ & 7.02 & 1.73 \\
Conductivity at 25 ${ }^{\circ} \mathrm{C}\left(\mu \mathrm{S} \mathrm{cm}^{-1}\right)$ & 24.3 & 295.0 & $\mathrm{MnO}(\%)$ & 0.08 & 0.03 \\
TOC (\%) & 0.40 & 0.65 & $\mathrm{CaO}(\%)$ & 0.10 & 44.85 \\
Sand (\%) & 60 & 35 & $\left.\mathrm{MgO}^{2} \%\right)$ & 2.29 & 1.20 \\
Silt (\%) & 28 & 30 & $\mathrm{Na}_{2} \mathrm{O}(\%)$ & $<0.20$ & $<0.20$ \\
Clay (\%) & 7 & 15 & $\mathrm{~K}_{2} \mathrm{O}(\%)$ & 2.33 & 0.75 \\
Kaolinite (\%) & $69-75$ & $4-7$ & $\mathrm{TiO}_{2}(\%)$ & 1.50 & 0.12 \\
Quartz (\%) & $6-16$ & $3-5$ & $\mathrm{P}_{2} \mathrm{O}_{5}(\%)$ & 0.21 & 0.07 \\
Calcite (\%) & 0 & $73-77$ & $\mathrm{~L}_{0} \mathrm{ignition}(\%)$ & 11.80 & 37.23 \\
\hline
\end{tabular}

\section{Equilibrium Isotherms}

Figure 1 shows the equilibrium isotherms between the gas and solid phases for the five tests performed with granitic soil.

In the experiments conducted with granite, it was observed that for both levels of contamination of nbutanol (Figure 1a), the concentration of benzene in the gas and solid phases increased with successive benzene additions until the solid phase saturation was reached. Then, only the gas phase concentration increased. Solid phase saturation concentrations of approximately $18 \mathrm{mg} \mathrm{kg}^{-1}$ were similar for both levels of n-butanol contamination.

The tests performed in limestone contaminated with n-butanol showed an isotherm shape type II according to IUPAC, (Ryu et al., 1999), corresponding to a multi-layer adsorption. The saturation point of its monolayer occurred for gas phase concentrations close to $45 \mathrm{mg} \mathrm{L}^{-1}$, corresponding to solid phase concentrations of $35 \mathrm{mg} \mathrm{kg}^{-1}$ and $22 \mathrm{mg} \mathrm{kg}^{-1}$, respectively, for the lower and the higher n-butanol contamination levels.

A distinct behaviour was observed in granite contaminated with both two levels of biodiesel contamination (Figure 1b). The lower level showed a similar trend to that shown by n-butanol curves, although with higher saturation concentrations $\left(\approx 36 \mathrm{mg} \mathrm{kg}^{-1}\right)$. The tests performed with higher biodiesel concentrations for both granite and limestone suggest that part of the benzene is trapped by biodiesel that constitutes a nonaqueous liquid phase (Figure $1 \mathrm{~b}$ and $\mathrm{d}$ ). Limestone contaminated with lower levels of biodiesel follows an isotherm type II with saturation point of $52 \mathrm{mg} \mathrm{kg}^{-1}$.

In all situations it was found that the sorption process was strongly influenced by the type of the soil, e.g. genesis, mineralogy and texture. 
The partition of benzene by the different phases of the soil was significantly affected by the presence of biofuels, being more pronounced for the highest concentration of biodiesel.

Freundlich, Langmuir and polynomial models were fitted to the experimental obtained results. The best fits parameters for each model are shown in Figure 2.

The effects of the addition of biofuels (n-butanol and biodiesel) to the sorption of benzene for the two studied soils (granite and limestone) and the three isotherms models are summarized in Figure 2. For the Freundlich isotherm fitting (Figure 2a), it was possible to state that:

- The constant $\mathrm{K}_{\mathrm{F}}$ showed a net decrease when n-butanol was present.

- The same behaviour was also observed when biodiesel was added in small quantities; nevertheless, larger additions showed the opposite effect.

- For limestone, the behaviour of $\mathrm{K}_{\mathrm{F}}$ was similar to that revealed by granite when $\mathrm{n}$-butanol was added. The addition of biodiesel in limestone did not show expressive effects on the soil sorption capacity.

- The exponent $\mathrm{n}$ trended to values less than one, which indicated a low sorption capacity according to Weber et al. (1996).

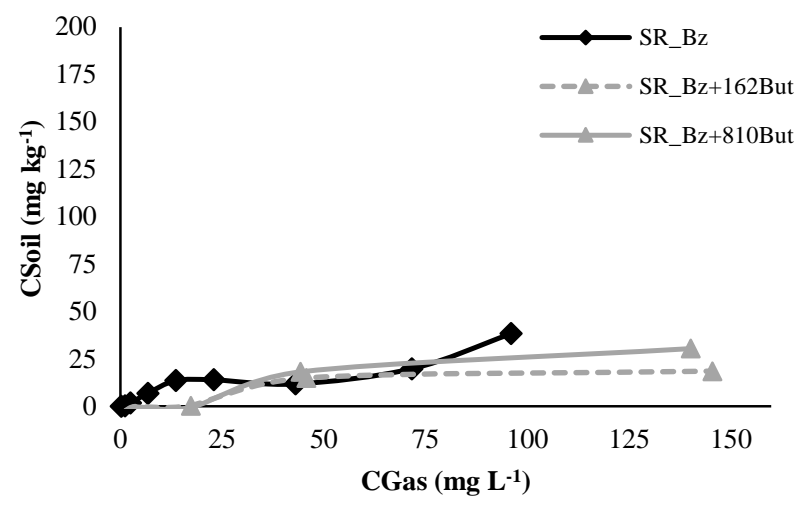

(a)

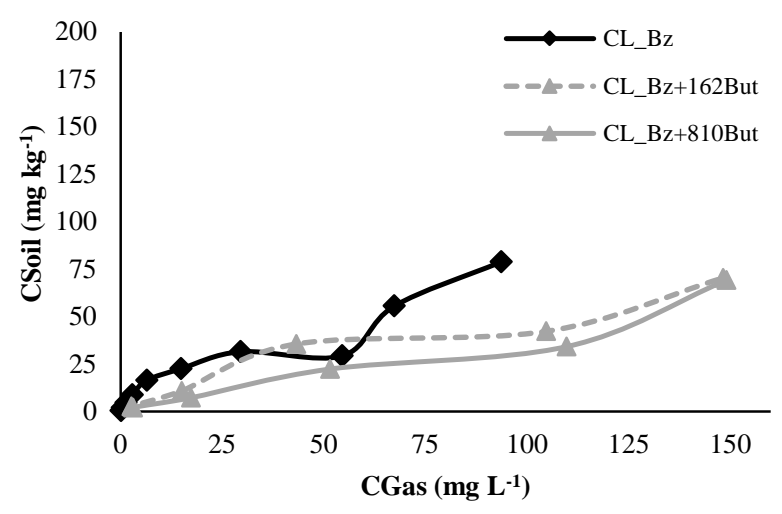

(c)

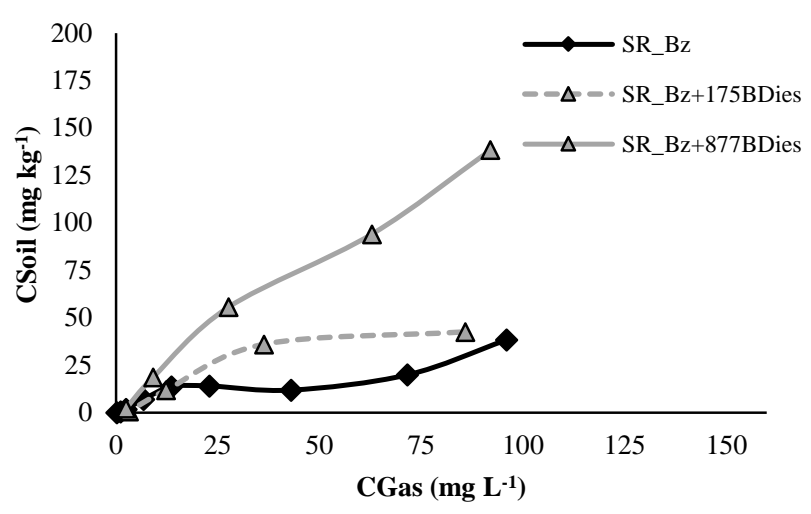

(b)

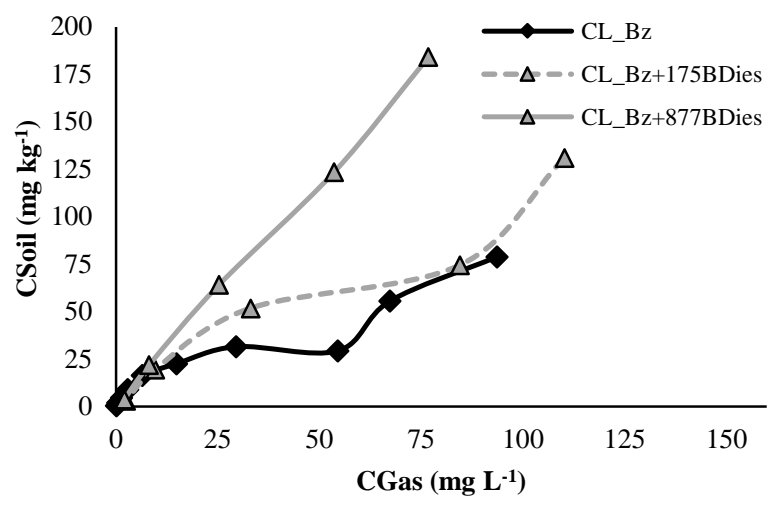

(d)

Figure 1. Benzene equilibrium isotherms of: (a) Granitic soil (SR) with different concentrations of n-butanol (162 and $810 \mathrm{mg} \mathrm{kg}^{-1}$ ); (b) Granitic soil with different concentrations of biodiesel (175 and $877 \mathrm{mg} \mathrm{kg}^{-1}$ ); (c) Limestone

(CL) with different concentrations of n-butanol (162 and $810 \mathrm{mg} \mathrm{kg}^{-1}$ ); (d) Limestone with different concentrations of biodiesel (175 and $877 \mathrm{mg} \mathrm{kg}^{-1}$ ).

Concerning the Langmuir model, the intrinsic parameters (Figure 2b) showed an unsystematic behaviour compared to the Freundlich model. In effect, the Langmuir equilibrium constant showed high variations, namely it significantly increased in the granitic soil with the additions of n-butanol and with higher additions of biodiesel while in limestone the same occured for the lowest n-butanol addition. On the other hand, the 
constant decreased for the remaining cases. The asymptotic maximum solid-phase concentration (Perry et al., 1984), represented by parameter b, suggested that it had a negative correlation with the equilibrium constant $\mathrm{K}_{\mathrm{L}}$, whereas $\mathrm{b}$ was lower when $\mathrm{K}_{\mathrm{L}}$ was higher.

The polynomial model is not as relevant as the previous ones, since it should only be selected if the Freundlich and/or Langmuir models are not appropriate to the data. However it was verified (Figure 2c), that the coefficient of the second degree term is always equal to 1 , which restricts valid conclusions regarding to the effect of biofuels addition.

Figure $2 \mathrm{~d}$ shows the obtained values for the coefficient of determination $\left(\mathrm{R}^{2}\right)$. In the three models, limestone fits better than granitic soil as it has higher values for $\mathrm{R}^{2}$. In granite, the coefficients of determination for the Freundlich and Langmuir models are identical but larger than the one obtained in the polynomial model.

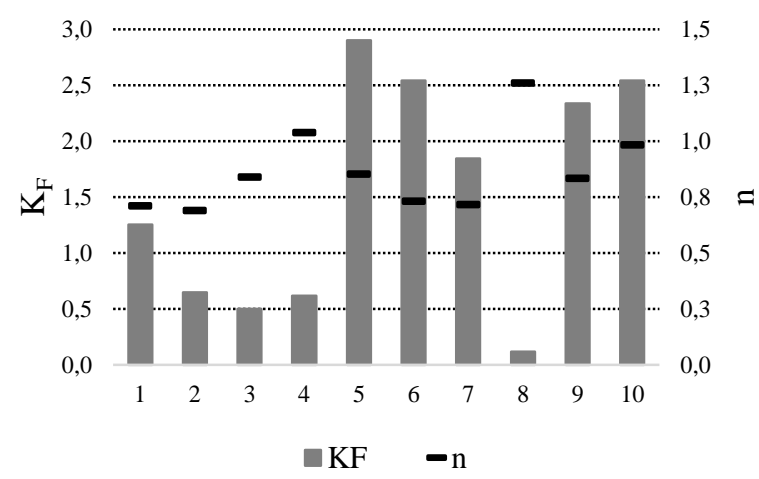

(a)

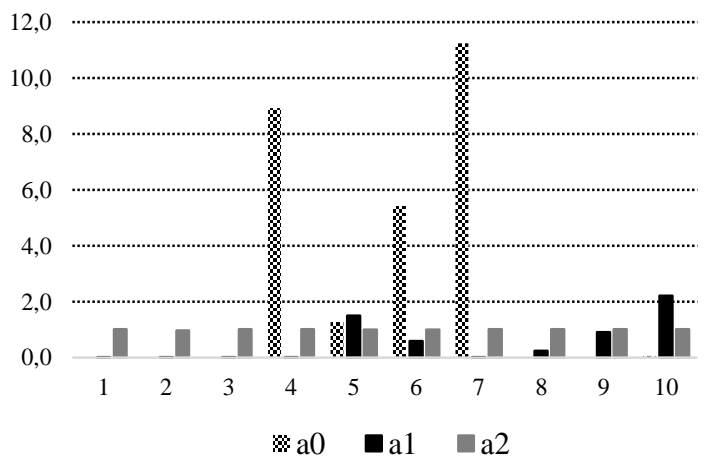

(c)
1. SR_Bz
2. SR_Bz+162But
6. $\mathrm{CL}_{-} \mathrm{Bz}$
7. $\mathrm{CL} \_\mathrm{Bz}+162 \mathrm{But}$

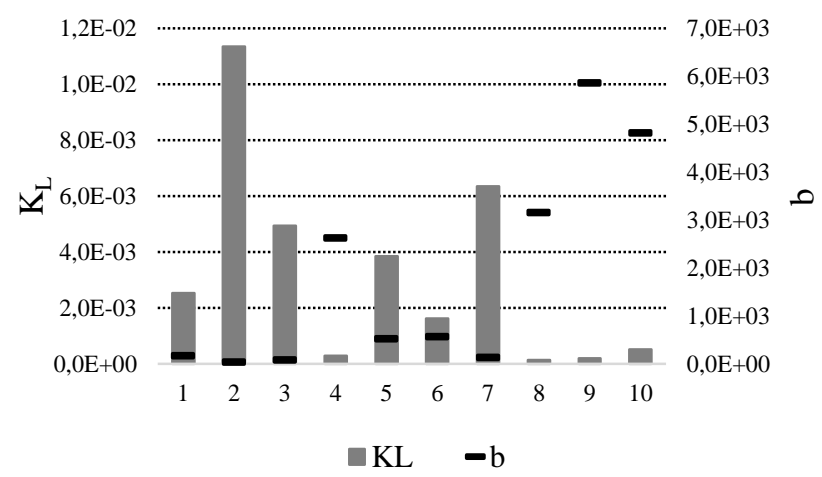

(b)

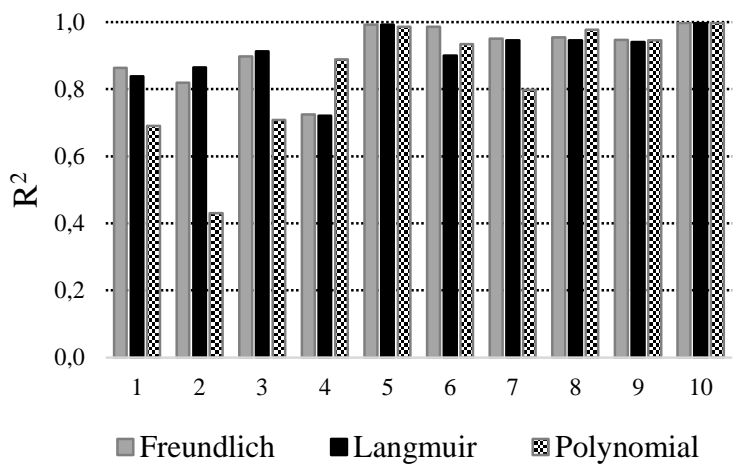

(d)
5. SR_Bz+877BDies

10. CL_Bz+877BDies

Figure 2. Parameters obtained for the equilibrium isotherms modeling: (a) Freundlich model (KF and n); (b) Langmuir model (KL and b); (c) Polynomial model (a0, a1 and a2). (d) Coefficient of determination ( $\mathrm{R}^{2}$ ) for all tested models.

\section{Conclusion}

The present work allowed us to compare the effects of the addition of two different biofuels (n-butanol and biodiesel) to the sorption of benzene in two different natural subsoils: granite and limestone. In all tested situations, it was found that the sorption process was strongly conditioned by the nature of the soil. The partition of benzene by different phases of the soil was considerably affected by the presence of biofuels. For the same biofuel and for the same type of soil, the favourability of benzene sorption did not seem to have a direct correlation with the concentration of the biofuel. Although the three isotherms (Freundlich, Langmuir and polynomial) showed a good agreement between experimental and fitted data, it is advised to adopt the Freundlich equation in future sorption process simulations, due to its lower complexity and the higher obtained coefficients of determination. 


\section{Acknowledgements}

This work was supported by FEDER funds through the Operational Program for Competitiveness Factors COMPETE and National Funds through FCT (the Portuguese Science and Technology Foundation) via the project PTDC/AAG-TEC/4403/2012 (ISIS).

\section{References}

Albergaria, J.T., Alvim-Ferraz, M.C., Delrue-Matos, C., 2010. Estimation of pollutant partition in sandy soils with different water contents. Environmental Monitoring and Assessment 171:171-180

Albergaria, J.T., Alvim-Ferraz, M.C., Delrue-Matos, C., 2012. Remediation of sandy soils contaminated with hydrocarbons and halogenated hydrocarbons by soil vapour extraction. Journal of Environmental Management 104:195-201

Cheng, H., Hu, E., Hu, Y., 2012. Impact of mineral micropores on transport and fate of organic contaminants: A review. Journal of Contaminant Hydrology 129-130:80-90

Dias, J.M., Alvim-Ferraz, M.C.M., Almeida, M.F., 2008. Comparison of the performance of different homogeneous alkali catalysts during transesterification of waste and virgin oils and evaluation of biodiesel quality. Fuel 87:35723578.

Indumathy, J., Cupples, A.M., 2013. Effect of isobutanol on toluene biodegradation in nitrate amended, sulfate amended and methanogenic enrichment microcosms. Biodegradation 24:657-663

Kinniburgh, D.G., 1986. General purpose adsorption isotherms. Environmental Science and Technology 20(9): 895-904

Mariano, A.P., Tomasella, R.C., Di Martino, C., Maciel Filho, R., Regali Seleghim, M.H., Contiero, J., de Angelis, D.D.F., 2009. Aerobic biodegradation of butanol and gasoline blends. Biomass Bioenergy 33(9):1175-1181

Mariano, A.P., Tomasella, R.C., Di Martino, C., Morais, E.B., Maciel Filho, R., Regali Seleghim, M.H., Contiero, J., Tauk Tornisielo, S.M., de Angelis, D.D.F., 2010. Aerobic biodegradation of butanol and diesel oil blends. African Journal of Biotechnology 9(42):7094-7101

Perry, R., Green, D., 1984. Perry's Chemical Engineers' Handbook (6 ${ }^{\text {th }}$ edition), McGraw-Hill.

Schaefer, C.E., Yang, X., Pelz, D., Tsao, D.T., Streger, S.H., Steffan, R.J., 2010. Aerobic biodegradation of iso-butanol and ethanol and their relative effects on BTEX biodegradation in aquifer materials. Chemosphere 81: 1104-1110

Ugwoha, E., Andresen, J.M., 2013. Impact of soil organic matter on the sorption and phase distribution of $20 \%$ butanolblended gasoline in the vadose zone. International Journal of Water Resources and Environmental Engineering 5(9):506-514

Weber, W.J., Digiano, F.A., 1996. Process dynamics in environmental systems. John Wiley \& Sons inc., New York. 